\section{Let's Strip the King: Eligibility Not Safety Is the Problem of Anticoagulation for Stroke Prevention in Elderly Patients With Atrial Fibrillation}

I $\mathrm{n}$ their retrospective follow-up study of all patients attending a hospital anticoagulant clinic for atrial fibrillation, Copland and colleagues ${ }^{1}$ found that the elderly population has both good anticoagulant control and a low incidence of hemorrhage while receiving warfarin therapy. Although interesting, from our point of view, these data cannot support the authors' general conclusion in favor of anticoagulant use. In fact, in the "Patients, Materials, and Methods" section, the authors note that prosthetic heart valve replacement was the only exclusion criterion, implicitly admitting the possibility of "a selection bias at the level of referral to the clinic."

We would like to comment on this bias with our recent data, ${ }^{2-4}$ reporting that global cognitive, functional, and comorbidity status strongly influence the assignment to aspirin or anticoagulant therapy in the elderly population both in the hospital and in the community. In particular, we also found that among general practitioners in the community, the assessment of the patients' walking independence is critical in the decision to start anticoagulation treatment. ${ }^{3,4}$

In light of these considerations, it is very likely that the patients attending the anticoagulant clinic in the study of Copland and colleagues ${ }^{1}$ were the most healthy, thus representing only a small proportion of total potential beneficiaries.

The question is not whether anticoagulation is effective to prevent stroke, but whether all elderly patients with atrial fibrillation may be considered eligible for warfarin treatment, even when poor health status might be an obstacle to compliance.

Giuseppe Bellelli, MD Angelo Bianchetti, MD Marco Trabucchi, MD Brescia, Italy

1. Copland M, Walker ID, Campbell Tait R. Oral anticoagulation and hemorrhagic complications in an elderly population with atrial fibrillation. Arch Intern Med. 2001;161:2125-2128.

2. Bellelli G, Rozzini R, Barbisoni P, Sabatini T, Trabucchi M. Geriatric assessment and anticoagulation in elderly patients with chronic atrial fibrillation [letter]. Arch Intern Med. 2000;160:2402.

3. Bellelli G, Bianchetti A, Trabucchi M. Anticoagulation to prevent stroke in atrial fibrillation: comprehensive geriatric evaluation should be routine before treatment is started [letter]. BMJ. 2000;321:1157.

4. Bellelli G, Guerini F, Bianchetti A, Trabucchi M. Anticoagulation in disabled patients [letter]. Arch Intern Med. 2002;162:107-108.

\section{In reply}

Bellelli et al raise 2 points. First, in our study, patients with prosthetic cardiac valves were excluded, thus introducing possible bias. However, although this is true, these patients make up only a small percentage of patients attending the anticoagulant clinic. They were excluded because they have a different target international normalized ratio of 3.0 to 4.5 compared with all other patients with atrial fibrillation (target international normalized ratio of 2.5), and are being treated with warfarin primarily because of their valve prosthesis and not atrial fibrillation.

Their second point is that less healthy, immobile patients may not have been initiated warfarin therapy and that there was bias at the level of referral to the clinic. We agree, and indeed had stated in the "Comment" section that there is likely to have been selection bias at the level of referral to the clinic. As regards mobility, it is noteworthy that $18 \%$ of patients attending our anticoagulant clinic are brought by the patient transport service, implying poor mobility. Therefore, immobility may not have been a major deterrent to initiation of warfarin therapy in our cohort. A recent study by Kalra et al $^{1}$ showed that rates of stroke and major hemorrhage after anticoagulation in clinical practice were comparable to those obtained in randomized controlled trials for patients with atrial fibrillation. In their study, patients had a mean age of 77 years and more intercurrent morbidity than patients in the trials and the findings clearly show that the good results from clinical trials can be produced in the clinic and in general practice with adequate therapeutic monitoring. In addition, the study by Howitt and Armstrong ${ }^{2}$ found that fewer than $50 \%$ of patients with atrial fibrillation who were eligible to take warfarin for stroke prevention accepted it as treatment after the risks and benefits had been explained. We are not advocating the use of warfarin for all patients with atrial fibrillation regardless of comorbidity, but think that it should at least be given consideration in most elderly patients with atrial fibrillation.

Mhairi Copland, BSc, MBChB, MRCP Isobel D. Walker, MD, FRCP, FRCPath R. Campbell Tait, BSc, FRCP, MRCPath Glasgow, Scotland

1. Kalra L, Yu G, Perez I, Lakhani A, Donaldson N. Prospective cohort study to determine if trial efficacy of anticoagulation for stroke prevention in atrial fibrillation translates into clinical effectiveness. BMJ. 2000;320:1236-1239.

2. Howitt A, Armstrong D. Implementing evidence based medicine in general practice: audit and qualitative study of antithrombotic treatment for atrial fibrillation. BMJ. 1999;318:1324-1327.

\section{Prevalence of Gastrointestinal Symptoms in Patients With Type 2 Diabetes: A Population-Based Study}

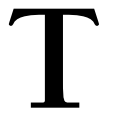

here has been a long-standing debate about whether gastrointestinal (GI) symptoms are more frequent in people with diabetes than in the nondiabetic population. ${ }^{1}$ However, most studies that have addressed this question have been limited by the use of 
Gastrointestinal (GI) Symptoms in Diabetic and Nondiabetic Subjects*

\begin{tabular}{|c|c|c|c|c|}
\hline \multirow[b]{2}{*}{ GI Symptom or Symptom Complex } & \multicolumn{2}{|c|}{ Prevalence, \% } & \multicolumn{2}{|c|}{ POR (95\% CI) } \\
\hline & $\begin{array}{l}\text { Subjects With } \\
\text { Type } 2 \text { Diabetes }\end{array}$ & $\begin{array}{l}\text { Control } \\
\text { Subjects }\end{array}$ & $\begin{array}{l}\text { Adjusted for Age } \\
\text { and Sex }\end{array}$ & $\begin{array}{l}\text { Adjusted for Age, Sex, } \\
\text { History of GI Events, and CVD† }\end{array}$ \\
\hline Frequent abdominal pain & 19.26 & 14.58 & $1.40(1.02-1.94) \ddagger$ & $1.22(0.84-1.78)$ \\
\hline Bloating & 29.78 & 26.47 & $1.18(0.90-1.55)$ & $1.02(0.75-1.39)$ \\
\hline Heartburn & 18.99 & 18.05 & $1.06(0.78-1.44)$ & $1.06(0.75-1.49)$ \\
\hline Nausea & 11.85 & 5.70 & $2.24(1.44-3.56) \ddagger$ & $1.76(1.06-3.00) \ddagger$ \\
\hline Vomiting & 2.97 & 2.78 & $1.06(0.51-2.19)$ & $0.72(0.32-1.60)$ \\
\hline Dysphagia & 5.94 & 4.06 & $1.50(0.86-2.64)$ & $1.48(0.80-2.80)$ \\
\hline Loose or watery stools & 13.05 & 7.35 & $1.88(1.26-2.88) \ddagger$ & $1.38(0.86-2.22)$ \\
\hline Urgency & 15.44 & 8.27 & $2.05(1.39-3.04) \ddagger$ & $1.47(0.95-2.30)$ \\
\hline$>3$ Bowel movements per day & 2.77 & 2.03 & $1.38(0.63-3.10)$ & $1.33(0.56-3.25)$ \\
\hline$<3$ Bowel movements per week & 3.51 & 3.87 & $0.91(0.48-1.71)$ & $1.32(0.63-2.77)$ \\
\hline Incontinence & 9.93 & 4.60 & $2.36(1.45-3.92) \ddagger$ & $1.93(1.12-3.38) \ddagger$ \\
\hline Esophageal symptoms (heartburn or dysphagia) & 21.91 & 19.41 & $1.16(0.87-1.56)$ & $1.15(0.83-1.61)$ \\
\hline Diarrhea symptoms§ & 18.85 & 11.42 & $1.81(1.29-2.56) \ddagger$ & $1.38(0.94-2.05)$ \\
\hline
\end{tabular}

*0ccurrence of symptoms often in the past 12 months. $\mathrm{N}=544 ; 4-13$ missing data. POR indicates prevalence odds ratio; $\mathrm{Cl}$, confidence interval.

†History of GI diseases and operations (any documented) (45 missing data) and presence of cardiovascular diseases (CVD) (any documented) (92 missing data).

$\ddagger P<.05$.

$\S$ More than 3 bowel movements per day, urgency, or loose or watery stools.

highly selected populations of people with diabetes and by the absence or inadequacy of control groups. In the September 10, 2001, issue of the ARCHIVES, Bytzer and colleagues ${ }^{2}$ reported results from a population-based study in Australia. They found 16 GI symptoms and 5 symptom complexes to have been significantly more frequent in the past 3 months in people with diabetes compared with nondiabetic controls, an association that was independent of age and sex. Among the people with diabetes there was no difference in the frequency of GI symptoms between those with type 1 or type 2 diabetes, with the exception of one symptom complex (any bowel movement). There was no association between GI symptoms and diabetes duration. Poor metabolic control was significantly associated with higher frequency of lumpy or hard stools, urgency, and the symptom complex of upper dysmotility symptoms. Only few associations were found for GI symptoms and the modus of therapy. However, presence of diabetes, therapy, and glycemic control were only assessed by self-report of the study subjects, and further variables, eg, history of GI diseases, presence of cardiovascular diseases (CVD), or late complications in diabetes, in particular, neuropathy, were not included.

Bytzer et al's results are in contrast to our own observations in Cambridge, England, ${ }^{3}$ in which we conducted a population-based, cross-sectional study. A total of 544 subjects with type 2 diabetes (mean \pm SD age, $63 \pm 8$ years; $64 \%$ men) were randomly selected from a local diabetes register. Mean \pm SD diabetes duration was $7.3 \pm 7.0$ years; $9 \%$ were treated with insulin, $66 \%$ with antidiabetic drugs (sulfonylureas, $52 \%$; metformin, $35 \%$; and acarbose, $2 \%$ ), and $27 \%$ were treated with diet only. The mean hemoglobin $A_{1 c}$ value was $7.9 \%$. In addition, 544 nondiabetic control subjects were recruited, individually matched for age, sex, and primary care practice. Clinical investigation included blood sampling and assessment of peripheral neuropathy in diabetic subjects. A detailed medical history was completed by interview including assessment of GI symptoms in the past 12 months using the questionnaire designed by Talley et al. ${ }^{4}$ This yields information about frequent abdominal pain, bloating, heartburn, nausea, vomiting, dysphagia, loose or watery stools, urgency, more than 3 bowel movements per day, less than 3 bowel movements per week, incontinence, and the symptom complexes esophageal symptom complex and diarrhea symptom complex. Overall, 11 of the 16 GI symptoms and 2 of the 5 symptom complexes described in the study by Bytzer et al could be evaluated using the same definitions.

Using multiple logistic regression analysis, we examined the association between GI symptoms and diabetes adjusting for age and sex. In a second model, we included history of GI diseases and operations and presence of CVD as potential confounding factors. Among the people with diabetes, the association of GI symptoms with age, sex, diabetes duration, treatment, and hemoglobin $A_{1 c}$ level was evaluated using logistic regression. In further models, history of GI diseases and presence of CVD as well as presence of peripheral neuropathy were included as additional predictors.

The Table presents prevalences of GI symptoms and symptom complexes in the diabetic and in the nondiabetic population, as well as prevalence odds ratios (PORs) for GI symptoms in diabetic compared with nondiabetic subjects. Adjusted for age and sex, 5 of the 11 GI symptoms and 1 symptom complex (abdominal pain, nausea, loose stools, urgency, and incontinence and the diarrhea symptom complex) were present significantly more frequently in patients with type 2 diabetes. No significant association was found for bloating, heartburn, vomiting, dysphagia, bowel movements more than 3 times per day or less than 3 per week, and the esophageal symptom complex. After additional adjustment for history of GI diseases and presence of CVD, only nausea and incontinence remained significantly associated with diabetes.

Among the people with diabetes, there was no significant association between GI symptoms and glycemic control or diabetes duration after adjustment for age 
and sex. Intake of oral antidiabetic drugs was significantly associated with frequent abdominal pain (POR, $2.51 ; 95 \%$ confidence interval $[\mathrm{CI}], 1.42-4.61)$, nausea (POR, 2.45; 95\% CI, 1.22-5.27), vomiting (POR, 8.27; 95\% CI, 1.60-71.36), and insulin therapy with vomiting (POR, 7.62; 95\% CI, 1.16-43.83). Further adjustment for history of GI diseases or operations and presence of CVD did not change the associations substantially.

In contrast to the results of the study by Bytzer et al, ${ }^{2}$ our study therefore found only 5 symptoms that were associated with diabetes, which was reduced to only 2 (nausea and incontinence) after adjustment for history of GI diseases and presence of CVDs. Furthermore, whereas Bytzer et al found differences in the prevalences of GI symptoms in people with diabetes taking and not taking oral antidiabetic drugs only for 1 symptom (anal blockage), our study evaluated oral antidiabetic drug use to be significantly associated with abdominal pain, nausea, and vomiting. The latter finding seems to be probable, as GI symptoms are often reported side effects of oral antidiabetic drug use, in particular, metformin and acarbose. These different results of the studies may be in part be explained by different time periods of GI symptoms (3 vs 12 months), data assessment (written self-report vs investigation and interview), the higher number of diabetic subjects in the present analysis (544 vs 423), adjustment for further variables in the present study, or region (Australia vs United Kingdom). Nevertheless, as we already reported from an earlier study, ${ }^{5}$ we propose that only few GI symptoms are more common in diabetic compared with nondiabetic subjects, particularly when adjusting for GI history and CVD, and that GI symptoms in diabetic subjects can be partly attributed to the side effects of oral antidiabetic drug use.

Andrea Icks, MD, PhD
Burkhard Haastert, PhD
Wolfgang Rathmann, MD, MSPH
Düsseldorf, Germany
Nick Wareham, MD
Cambridge, England

This study was supported by the ministries of science and of health and welfare of Northrhine-Westfalia, and by a research grant from Solvay Pharmaceuticals, Hannover, Germany.

1. Maleki D, Locke GR, Camilleri M, et al. Gastroinestinal tract symptoms among persons with diabetes mellitus in the community. Arch Intern Med. 2000;160: 2808-2816.

2. Bytzer P, Talley NJ, Leemon M, Young LJ, Jones MP, Horowitz M. Prevalence of gastrointestinal symptoms associated with diabetes mellitus: a populationbased survey of 15000 adults. Arch Intern Med. 2001;161:1989-1996.

3. Rathmann W, Haastert B, Icks A, et al. Low faecal elastase 1 concentrations in type 2 diabetes mellitus. Scand J Gastroenterol. 2001;36:1056-1061.

4. Talley NJ, O'Keefe EA, Zinsmeister AR, Melton LJ. Prevalence of gastrointestinal symptoms in the elderly: a population-based study. Gastroenterology. 1992; 102:895-901

5. Enck P, Rathmann W, Spiekermann M, et al. Prevalence of gastrointestinal symptoms in diabetic patients and in non-diabetic subjects. Z Gastroenterol. 1994;32:637-641

\section{In reply}

Dr Icks et al raise a number of issues pertaining to our recently published article. First, in contrast with our findings, they propose that only nausea and incontinence are more common in pepole with diabetes compared with nondiabetic controls. Their conclusion is based on a study of subjects with diabetes selected from a diabetes register compared with 544 control subjects. Unfortunately, Icks et al did not detail how the control subjects were recruited: were they population controls or nondiabetic patients from outpatient clinics or from primary care practices? More important, subjects with diabetes and nondiabetic controls were not exposed to the same method of data sampling, as only diabetic subjects were assessed clinically, and this may have introduced bias. One of the strengths of our study is the recruitment of both diabetic subjects and nondiabetic controls from the same populationbased sample.

Second, Icks et al suggest that other GI diseases and the presence of CVD should have been included as potential confounding factors and that this may have altered our results. We cannot exclude such a possibility. A more complete analysis, outside the scope of our study, should include all known potential risk factors that may be important in the pathogenesis of GI symptoms, including psychosocial distress, ${ }^{1}$ alcohol ingestion, obesity, diabetic complications, and use of drugs, ${ }^{2}$ to name a few, and such a largescale community-based study is warranted.

Finally, they suggest that GI symptoms in diabetic subjects can be attributed to the side effects of oral hypoglycemic drug use. We have recently published the results of a large analysis of GI symptoms in 956 subjects with type 2 diabetes. ${ }^{3}$ We found that troublesome GI symptoms were not associated with use of oral hypoglycemic drugs, except for diarrhea and fecal incontinence, which were strongly and independently associated with metformin use. These findings have been confirmed by others. ${ }^{4}$

We encourage Dr Icks and colleagues to publish their interesting results in full. A more complete description of the recruitment of subjects, the methods used, and the results might add valuable input into the design of future studies of the pathogenesis of GI symptoms in diabetes.

Peter Bytzer, MD, PhD

Nicholas J. Talley, MD, PhD

Sydney, Australia

1. Talley SJ, Bytzer P, Hammer J, Young L, Jones M, Horowitz M. Psychological distress is linked to gastrointestinal symptoms in diabetes mellitus. Am J Gastroenterol. 2001;96:1033-1038.

2. Bytzer P, Hallas J. Drug induced symptoms of functional dyspepsia and nausea: a symmetry analysis of one million prescriptions. Aliment Pharmacol Ther. 2000;14:1479-1484.

3. Bytzer P, Talley NJ, Jones MP, Horowitz M. Oral hypoglycaemic drugs and gastrointestinal symptoms in diabetes mellitus. Aliment Pharmacol Ther. 2000; 15:137-142.

4. Lysy J, Israeli E, Goldin E. The prevalence of chronic diarrhea among diabetic patients. Am J Gastroenterol. 1999;8:2165-2170.

\section{Weight Loss: Goals, Realities, and Strategies}

T very much enjoyed the article "Obese Patients' Perceptions of Treatment Outcomes and the Factors That Influence Them" by Foster et al, ${ }^{1}$ and would like to contribute a few comments. It is clear that there 
is a mismatch between obese patients' and their physicians' weight loss goals (for the patients!). Patients are driven by body image concerns, which require large weight losses. Although physicians would also like to help patients achieve their goals, we are also influenced by the knowledge that a relatively small weight loss is not only realistic, but also worthwhile, for health enhancement. It is clear that until we are able to consistently facilitate large weight losses, one of our main tasks is to convince patients that health enhancement with moderate weight loss should be an alternate goal, that weight loss short of body image ideal should be viewed as health success rather than (or at least in addition to) body image failure. For our part, we should not view our efforts as total failures if our patients do not accomplish immediate weight loss. If patients' attitude changes are necessary before they can commit themselves to working on lifestyle changes for modest but long-term weight loss, physicians' contributions should be viewed as incremental, helping patients move forward along the "stages of change" continuum. In my own practice, I have found it useful to focus on exercise recommendations, and to consistently praise any diet or exercise successes (patients tend to dismiss their small steps in the right direction).

Daniel Reinharth, MD East Meadow, NY

1. Foster GD, Wadden TA, Phelan S, Sarwer DB, Swain Sanderson R. Obese patients' perceptions of treatment outcomes and the factors that influence them. Arch Intern Med. 2001;161:2133-2139.

\section{Are There Benefits From Long-ferm Pharmacotherapy of Obesity?}

I studied the review of pharmacotherapy for obesity by Glazer ${ }^{1}$ in the August 13/27, 2001, issue of the ARCHIVES. The author defined efficacy using the surrogate of weight loss rather than looking at clinical outcome measures. The review based its conclusion on the principle that if you define your standards low enough, you can be successful at anything. A weight loss of $17 \mathrm{lb}$ $(7.6 \mathrm{~kg})$ in excess of placebo is the evidence-based support of long-term obesity pharmacotherapy. This conclusion seems unwarranted since no tangible outcome benefit has been demonstrated. ${ }^{1}$ Not only does the practitioner reject this as a successful therapy, but patients also regard these modest benefits as disappointing. ${ }^{2}$
I respectfully submit that the evidence needed to convince the prudent clinician includes a significant benefit in survival, function, or disease reduction. Before an expensive and dangerous approach can be adopted, the bariatric research community must accept a standard established when demonstrating a value for treatment of hypertension and hypercholesterolemia. Swedish investigators have recognized this in their report of bariatric surgery. ${ }^{3}$

To meet this challenge, a large, multicenter, randomized, placebo-controlled trial is needed. The magnitude of this problem, and the tremendous profits derived from its treatment, should prompt the government and private sources to fund studies designed to establish objective clinical benefits for this approach that arguably has caused more harm than good. This failed approach includes the use of human chorionic gonadotropin injections, amphetamines, ${ }^{4}$ thyroid hormone supplementation, dexfenfluramine, and fenfluramine. To invoke the mantra of an evidence-based approach when the drug cited as having the greatest benefit is primarily supported by a 1968 study with level II evidence betrays a basic misunderstanding of this paradigm. We believe that this review fails to present credible evidence that patient outcome is improved through the use of drugs for treating obesity. Even the improvement in the surrogate end point of weight loss is limited and supported by industry-supported trials with methodological flaws.

With the stigma associated with heart valve damage, ${ }^{5}$ addictive potential, ${ }^{6}$ and the rebound phenomenon, it is time to stop pandering to the pharmaceutical industry. Rather, they should support the bariatric community by funding meaningful studies designed to demonstrate outcome benefits that will convince clinicians who use an evidence-based approach.

Patrick Kearns, MD San Jose, Calif

1. Glazer G. Long-term pharmacotherapy of obesity 2000. Arch Intern Med. 2001; 161:1814-1824.

2. Foster GD, Wadden TA, Phelan S, Sarwer DB, Swain Sanderson R. Obese patients' perceptions of treatment outcomes and the factors that influence them. Arch Intern Med. 2001;161:2133-2139.

3. Sjostrom L, Larsson B, Backman L, et al. Swedish Obese Subjects (SOS): recruitment for an intervention study and a selected description of the obese state. Int J Obes Relat Metab Disord. 1992;16:465-479.

4. Bray G. Use and abuse of appetite-suppressant drugs in the treatment of obesity. Ann Intern Med. 1993;119:707-713.

5. Connolly H, Carary J, McGoon MD. Valvular heart disease associated with fenfluramine-phentermine. N Engl J Med. 1997;337:581-588.

6. Long-term pharmacotherapy in the management of obesity: National Task Force on the Prevention and Treatment of Obesity. JAMA. 1996;276:1907-1915. 